NÚMERO 5 | febrero - julio 2022 | 103-125

Revista de teoría literaria y literatura comparada

DOI: 10.22201/ffyl.nuevaspoligrafias.2022.5.1482

Recibido: 12-02-2021 | Aceptado: 27-04-2021

\title{
EL RECURSO DE LAS IMÁGENES Y FOTOGRAFÍAS EN CINCO ANTOLOGÍAS SOBRE LA Generación del 27: Gerardo Diego (1932), Vicente Gaos $(1965,1975)$, José Luis CANo (1982) y Víctor de LAMA (1997)
}

\author{
The Use of Images and Photographs in Five Anthologies of the Generation of '27: \\ Gerardo Diego (1932), Vicente Gaos (1965, 1975), José Luis Cano (1982), \\ AND VÍCTOR DE LAMA (1997)
}

Luis Gabutti Alarcón

Posgrado en Letras

Universidad Nacional Autónoma de México | México

Contacto: 1.gabutti292@gmail.com

\begin{abstract}
Resumen
En el presente trabajo se estudia el empleo de imágenes y fotografías en cinco antologías sobre la Generación del 27: Poesía española. Antología 1915-1931 de Gerardo Diego (1932), las dos ediciones de Antología del grupo poético de 1927 de Vicente Gaos (1965, 1975), Antología de los poetas del 27 de José Luis Cano (1982) y Poesía de la generación del 27. Antología crítica comentada de Víctor de Lama (1997). También se plantea que los recursos visuales en ellas obedecen a unas reglas de combinación establecidas por el repertorio antológico sobre esta agrupación literaria para establecer imágenes de autor de tres maneras distintas: para figurar a los poetas antologados a partir de retratos de cada uno; al antólogo como creador del libro; y a la presentación grupal a partir de la fotografía del Centenario de Góngora en Sevilla en 1927. Para demostrar lo anterior se recurre a entender la antología como un libro coherente según las reflexiones de José Francisco Ruiz Casanova y su inserción en el sistema literario según Itamar Even-Zohar. Asimismo, para analizar la importancia de las imágenes, se emplean los conceptos de configuración y figuración
\end{abstract}

\begin{abstract}
In this work we study the use of images and photographs in five anthologies of the Generation of '27: Poesía Española. Antología 1915-1931 by Gerardo Diego (1932), the two editions of Antología del grupo poético de 1927 by Vicente Gaos (1965, 1975), Antología de los poetas del 27 by José Luis Cano (1982), and Poesía de la generación del 27. Antología crítica comentada by Víctor de Lama (1997). We propose that the visual elements in the mentioned anthologies follow some specific rules established by the anthological repertoire about this literary group to set author images in three different ways: to configure the anthologized poets from portraits of each one of them, the anthologist as the book creator, and the group presentation from the photography of the Gongora's Centennial in Sevilla in 1927. To prove this, the anthology is understood as a coherent book according to José Francisco Ruiz Casanovas considerations and its insertion into the literary system, following Itamar Even-Zohar's notes. Moreover, to analyse the importance of the images, we use the concepts of configuration and
\end{abstract}


que establece Dominique Maingueneau. La importancia de esto radica en entender las antologías poéticas sobre la Generación del 27 como parte de un repertorio en donde existen elementos y reglas de combinación para establecer modelos no sólo en la selección poética, sino también en los recursos visuales que utilizan.

Palabras clave: Generación del 27; antologías poéticas; recursos visuales; imágenes de autor figuration pointed out by Dominique Maingueneau. The importance of this study is to understand the poetic anthologies of the Generation of '27 as part of a repertoire where there are elements and rules of combination that establish models not only in the poetic selection but also in the visual elements that are used on them.

Keywords: Generation of '27; poetic anthologies; visual elements; author images

a Generación de 1927 es una de las agrupaciones poéticas más importantes de España por los poemarios y poemas que legaron a la historia de la literatura; sin embargo, la lectura de esos textos no sería posible sin la impronta de las antologías que han abastecido al mercado editorial y escolar para difundirlos. Estos libros son productos para los que los antólogos optan por seleccionar textos ejemplares y representativos de un repertorio ya existente de autores y obras. Dentro de ese repertorio existen otros elementos: las posturas críticas ante el material seleccionado, los autores canónicos, los escritores marginados y algunos recursos visuales para figurar a estos poetas y textos seleccionados. Para este trabajo, centro mi atención en el uso de imágenes en algunas antologías sobre los poetas del 27 porque se emplean para figurar la presencia autoral de antólogos y poetas, además de caracterizar colectivamente a estos escritores, ya que permiten al lector conocer y dotar esa imagen con nuevos sentidos según la disposición material de la antología. Debido a eso, estos elementos visuales son seleccionados por el antólogo o la editorial para reforzar el contenido de las antologías.

Los estudios sobre las antologías poéticas del 27 se centran en los florilegios de Gerardo Diego Poesía española. Antología 1915-1931 (1932) y Poesía española contemporánea (1934) con trabajos sobre la creación de este libro y su recepción (Morelli, 1997) y sobre las poéticas que aparecen de los autores que anteceden la selección de textos (Pozuelo Yvancos, 2009). Las investigaciones que han revisado antologías 
coetáneas o posteriores a la de Diego son las de Marta Palenque (2007) y Andrew A. Anderson (2005), quienes las abordan desde un aspecto histórico y su circulación en el sistema literario, mientras que las reflexiones de Jacques Issorel $(1984,1993,2000)$ y Francisco Javier Díez de Revenga $(1987,2004)$ aportan un acercamiento descriptivo en torno a estos libros y cómo sirven para difundir a estos poetas. En cambio, los trabajos de Miguel Ángel García $(2016,2017)$ y Christoph Rodiek (1998) se interesan en analizar la representación de los poemas escogidos en algunas de estas antologías. De los seis críticos mencionados, desprendo tres perspectivas: estas antologías sirven para la difusión de estos escritores, se insertan en el sistema literario para establecer la construcción de una agrupación poética y, finalmente, existe una representación de los poemas seleccionados en las antologías para forjar un canon o un tipo de lectura. Sin embargo, en estos trabajos, se deja de lado el uso de imágenes en dichas antologías porque se centran exclusivamente en el texto y los criterios de selección.

El gran corpus de antologías sobre el 27 nos indica distintas maneras de elaboración por parte de los antólogos. Algunos, como Andrés Soria Olmedo (2007), añaden a la selección poética otros escritores coetáneos (Juan Larrea, José María Hinojosa, Fernando Villalón, Juan José Domenchina, etcétera) aparte de los diez usuales (Pedro Salinas, Jorge Guillén, Gerardo Diego, Vicente Aleixandre, Federico García Lorca, Dámaso Alonso, Emilio Prados, Luis Cernuda, Rafael Alberti, Manuel Altolaguirre). Otros optan por organizar a los poetas y textos escogidos de manera cronológica (Francisco Javier Díez de Revenga, 2007), alfabética (Ángel González, 2004) o temática (Gaspar Garrote Bernal [1994], que agrupa la poesía según el movimiento estético que representen).

Podemos observar en algunas imágenes de estas antologías, como la de Pedro C. Cerrillo (2002), el empleo de fotografías e ilustraciones de revistas de la época en el prólogo - no así en la parte de la selección poética-. Lo mismo sucede con la antología de Manuel Cifo González (1996), en su "Estudio de la poesía de la generación del 27” o en la sección ilustrada de la antología de Arturo Ramoneda (1990). De igual manera, existen otras que emplean ilustraciones que acompañan a los poemas, como la de Esperanza Ortega (1987) o la de Amalia Roldán y Lola Valle (2007), que se enfocan en lectores de educación básica. Por otro lado, hay varias que no emplean ninguna imagen en el cuerpo del libro salvo la portada, como la segunda edición de la de Ángel González (2004); la de Joaquín González Muela y Juan Manuel Rozas (1966); o la de José Ricart (2014). 
Ante tan vasto corpus de florilegios, escojo cinco: Poesía española. Antología 1915-1931 de Gerardo Diego (1932), las dos ediciones de Antología del grupo poético de 1927 de Vicente Gaos (1965, 1975), Antología de los poetas del 27 de José Luis Cano (1982) y Poesía de la generación del 27. Antología crítica comentada de Víctor de Lama (1997) por permitirnos observar una evolución diacrónica de una serie de elementos visuales en común de estos libros como lo es el uso de la figura del antólogo, de los retratos de los poetas antes de su selección poética y del uso de la fotografía del Centenario de Góngora en Sevilla en 1927.

El libro de Diego se publicó en 1932 en la editorial Signo (Madrid) y, si antes había antologías que reunían a algunos autores que designamos parte de la Generación del 27, este compendio del santanderino consiguió centralizar en el campo literario a estos poetas, además de ser el primero sobre la Generación del 27 que empleó fotografías de los autores seleccionados para figurarlos antes de la selección poética. Por su parte, la antología de Gaos fue la primera en publicarse con el rótulo de "Grupo poético de 1927" para satisfacer la demanda de material escolar ante la incorporación de estos escritores en el sistema educativo (Anderson, 2005: 166). En este trabajo empleo la edición de Anaya de 1965 que sólo recurre a usar la icónica fotografía de 1927 en Sevilla en la contraportada y la edición de Cátedra de 2019 (Trigesimotercera edición de la de 1975) que acude a la ilustración de los poetas seleccionados antes de sus correspondientes selecciones poéticas. Los florilegios de Cano y Lama son parte de las publicaciones para satisfacer tanto a un público general como a uno escolar y comparten, con la antología de Diego y Gaos, el uso de imágenes para figurar a los escritores y el empleo de la fotografía en Sevilla en 1927.

En ese sentido, considero que las imágenes empleadas son elementos pertenecientes a un repertorio antológico en el cual existen ciertas reglas de combinación para desarrollar el producto en donde van a ser usadas en el corpus que se analizará. La investigación parte de la siguiente premisa: el uso de elementos visuales funciona para establecer imágenes de autor dadas por el antólogo y la editorial con el fin de configurar y figurar a los poetas seleccionados, pero también de dotar con una imagen simbólica al grupo seleccionado y de conferir de autoridad al antólogo. El objetivo principal de este trabajo reside en concebir los sentidos que aportan estos recursos visuales a las antologías, además de observar un uso habitual de algunas de ellas, identificar su capacidad simbólica y valorar su empleo. Para realizar lo mencionado, primero, debemos entender la materialidad de las antologías; segundo, ubicar 
y clasificar las imágenes que aparecen en ellas; tercero, analizar su uso en estos libros; cuarto, interpretar el sentido que tienen; y quinto, valorar su empleo.

Existen aproximaciones teóricas a las antologías poéticas que se centran en su función histórica como los trabajos de Alfonso Reyes (1997) y Estuardo Núñez (1959), que se interesaban en la vinculación de estos libros con las historias de la literatura, mientras que otros optan por estudiar su recepción como el de Morelli (1997), ya referido anteriormente. Sin embargo, estos acercamientos dejan de lado la materialidad de estos libros y optan por centrarse en los criterios de selección, el canon y la postura del antólogo ante la historia de la literatura. De los estudiosos más recientes sobre antologías, la perspectiva de José Francisco Ruiz Casanova (2007) resulta la más innovadora por considerar que la antología poética "es libro único en virtud de criterios estéticos, historiográficos, teórico-críticos, circunstancias cronológicas o coyunturales y también, por qué no, en virtud de arte combinatoria" (22). De esta manera, defiende la unidad y coherencia de la antología desde su forma como libro, la cual establece la poética (postura político-estética) del antólogo. No obstante, en su estudio falta considerar la materialidad de éstas, ya que existen diferencias materiales entre un libro antológico manuscrito, electrónico o impreso en el siglo xx. Estos contrastes materiales determinan la elaboración del producto, su relación con las instituciones de su época, su circulación en el sistema literario y su recepción en los lectores, como indica Roger Chartier (2009): "En efecto, cada forma, cada soporte, cada estructura de la transmisión y de la recepción de lo escrito afecta profundamente sus posibles usos e interpretaciones. En estos últimos años, la historia del libro se ha interesado en señalar, en diversos niveles, estos efectos de sentidos de las formas" (27).

Por lo anterior, resulta necesario que entendamos la correspondencia de la unidad material y textual que existe en las antologías con el sistema literario. Siguiendo la teoría de los polisistemas de Itamar Even-Zohar (1999: 23-52), la antología se inscribe como un producto dentro de uno de ellos; este libro se relaciona con el antólogo que funge como productor de ese material y el público lector que consume el libro según sus competencias. La anterior relación se da de manera horizontal, mientras que verticalmente la antología se involucra con la institución académica o estatal y el mercado escolar, literario o editorial. La creación de antologías se da a partir de las competencias que tiene el antólogo con el repertorio que existe de esos libros (antologías anteriores, la obra de los poetas, estudios críticos, investigaciones, etcétera), lo que le permite formular una serie de combinaciones de elementos y reglas para crear 
modelos. En ese sentido, la concepción de un "campo antológico" que maneja Carlos Guzmán Moncada (2000) sirve para entender esta relación entre el objeto antología y el sistema literario:

Definir un campo antológico supondría reconocer un conjunto de prácticas relacionadas por la existencia de un capital común y la lucha por su apropiación; identificar aquellas relaciones en las cuales se hace presente un habitus, una distinción de los que detentan y una pretensión de los que aspiran a apropiarse de dicho capital; así como determinar un sentido del juego, una complejidad objetiva condensada y reconocible en cada una de dichas prácticas, textuales e intertextuales en este caso, incomprensibles del todo sin la historia del campo de producción de éstas y que en ellas se manifiesta. (28)

El antólogo, en relación con el campo antológico, dispone de la selección y la ordena según sus fines o según lo demandado por las instituciones; de esta manera configura la antología para decidir si los poetas seleccionados solamente aparecerán a partir de notas biobibliográficas o si también se emplearán fotografías para representarlos. Ruiz Casanova (2007) establece, como primer punto para estudiar la antología poética, que "La recepción crítica debe de tomar la antología como libro, como obra con principio y fin, y no como pastiche o simple arte combinatoria o acumulativa. Desde este punto de vista, cabe juzgar el texto en sus valores de unidad, objetivos, coherencia y representatividad respecto de la poética del antólogo" (212). Por tal motivo, las imágenes que se insertan en la materialidad de las antologías sirven como mediaciones que ayudan a la configuración y figuración de los poetas y de los antólogos:

La "configuración" está orientada hacia el ajuste de la obra, pasa por varios géneros: manifiestos, debates, escritos sobre otras artes, prefacios a obras de otros escritores, obras sobre otros escritores... permite reorientar la trayectoria de conjunto en la cual se inscribe cada obra singular: ser escritor es también gestionar la memoria interna de sus textos y de sus actividades anteriores, y reorientarlas en función de un porvenir. A este trabajo de "configuración" se mezcla el trabajo de "figuración" a través del cual el actor, en cierto modo, se pone en escena como escritor: viaja o no, vive retirado en el campo o en el centro de una gran ciudad, sale en televisión o esconde su cana, concede entrevistas a la prensa, etc. (Maingueneau, 2015: 21) 
En Poesía española. Antología 1915-1931 (1932) (Figura 1), Diego se posiciona, desde la portada, como autor del libro y como poeta seleccionado en su propio florilegio. El santanderino, en el proceso de elaboración del compendio, indica a los seleccionados que requiere que le manden una biografía, una declaración poética, una selección propia de poesías, poesía inédita y una fotografía como se lee en la carta que le envía a Guillén el 26 de diciembre de 1930 (Morelli, 1997: 192). Resulta importante en Poesía española la integración de una fotografía por cada poeta por el hecho de representar no sólo la imagen personal y poética de los antologados (biografía y poética), sino también su presencia física (fotografía) para dar cuenta de su individualidad. Diego expone su foto, su biografía y su poética como uno más de los seleccionados; pero, también, da cuenta de su labor como antólogo y autor en el prólogo del libro, en donde refiere que su proyecto antológico fue un quehacer colectivo en el que buscaba poner de manifiesto la singularidad de cada uno de los seleccionados: "Y no obstante, como ya he dicho, hay un programa mínimo, negativo y una identidad común que une en cierta manera a todos estos poetas, aparte de los lazos de mutua estimación y recíproca amistad que los relacionan" (Diego, 2007: 92).

\section{Figura 1}

Cubierta de Poesía española. Antología 1915-1931 de Gerardo Diego. Madrid: Anaya, 1965

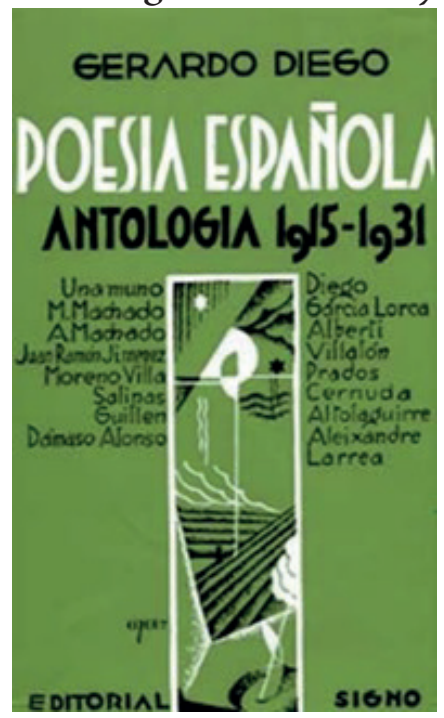

Fuente: recuperada de https://www.visor-libros.com/tienda/media/ catalog/product/cache/1/image/650x/040ec09b1e35df139433887a97daa 66f/e/s/especiales07_a_5.jpg 
Frente a la autoría de Diego como antólogo y como poeta autoseleccionado en su libro, la Antología del grupo poético de 1927 de Gaos (1965) (Figura 2) —primera antología que denomina a estos poetas como "Grupo poético de 1927" (Anderson, 2005: 164) - configura al antólogo como "Editor" en la cubierta y portada publicada en Biblioteca Anaya. Resulta significativa esta marca textual porque, si bien podemos considerar al antólogo como editor del material que selecciona, se invisibiliza su función autoral. Lo anterior, considero, se debe a lo siguiente: Diego, que ocupa dentro del campo literario el rol de poeta, llega a concebirse a sí mismo como creador y autor de su antología, aunque señale un trabajo colectivo de todos los seleccionados (Diego, 2007: 91); en cambio, Gaos, aunque también fuera poeta, se perfilaba en este ámbito como un crítico literario y en ese sentido invisibiliza su yo autoral. En la reedición actualizada por Carlos Sahagún para editorial Cátedra (1975), además de aparecer otra vez como editor en la cubierta y en la portada, se refieren al antólogo en la nota a "Esta edición" de la siguiente manera:

Este libro es básicamente reedición de la Antología del grupo poético de 1927 de Vicente Gaos (Salamanca, Anaya, 1965). La puesta al día es obra de Carlos

Figura 2

Cubierta de Antología del grupo poético de 1927 de Vicente Gaos, Madrid: Anaya, 1965

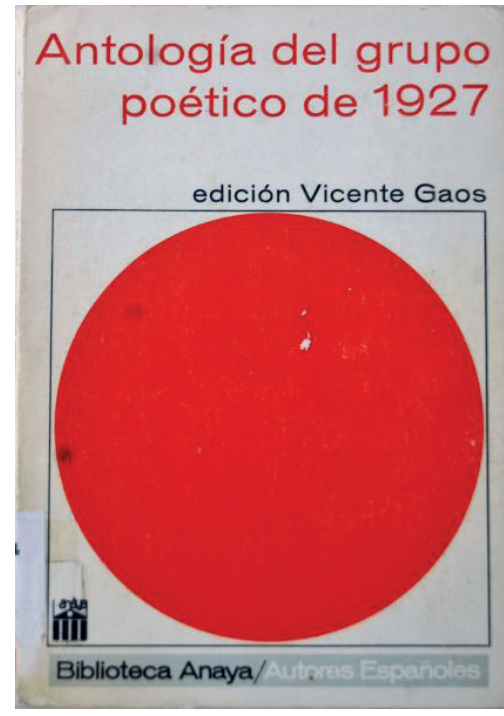

Fuente: Recuperada de https://www.fundacioncajasegovia.es/wpcontent/uploads/2017/02/824antologiapoetico1927.jpg 
Sahagún, que ha actualizado las notas bibliográficas, ha añadido poemas de libros posteriores a 1965 y ha corregido ocasionalmente erratas de la primera edición. (Gaos, 2019: 45)

Si bien estas marcas de autoría, sea como antólogo o como editor, nos señalan la configuración de los antólogos, estos elementos también se aprecian en los apartados de los poetas seleccionados, como se puede observar en la Poesía española. Antología 1915-1931 de Diego, que incluye la biografía, poética y fotografía de los escritores por él recopilados, y en la Antología del grupo poético de 1927 de Gaos, que en la edición de 1965 sólo establece apartados biobibliográficos y en la contraportada coloca la foto del Centenario de Góngora en 1927, mientras que en la edición de 1975 añade imágenes para figurar a los seleccionados. Los florilegios de Diego y Gaos han fungido como modelos en el campo antológico del 27 porque dan elementos y reglas para la creación de otras antologías sobre estos escritores: los poetas que se deben seleccionar, otros poetas que amplían la nómina generacional, el anteceder a la selección poética de cada escritor con una nota biobibliográfica para concebir la poesía de cada autor, el usar imágenes para figurar a los escritores, el emplear la fotografía del Centenario de Góngora en Sevilla, etcétera. Estos elementos se combinan según las competencias de los antólogos posteriores para crear nuevos libros; debido a lo anterior, los florilegios del santanderino y del valenciano se erigen como modelos para las antologías posteriores.

Este uso de fotografías resulta importante ya que confiere a los textos seleccionados una figuración que permite establecer otra percepción de la figura autoral de los escritores antologados. Así, en la antología de Diego los observamos en su juventud en los años treinta, mientras que en el compendio de José Luis Cano los vemos en su época madura. En ese sentido, debemos considerar que estas imágenes son también retratos de los poetas y que, como indica Joanna Woodall (1997): "Portraiture occupies a central position in the history of western art. It has been the most popular genre of painting and lies at the heart of the naturalist project. It has been crucial to the formation and articulation of 'individualism'" (xIII). La autora señala que la fotografía le permitió al retrato obtener relación visual objetiva entre la imagen y el modelo, además de una circulación mayor entre la clase media (Woodall, 1997: 6). De igual manera, habrá que entender a las fotografías en las antologías como una serie de conceptos que han sido determinados por el programa del dispositivo cámara, como indica Vilém Flusser (1990): "Desde el punto de vista del fotógrafo, lo importante de 
la fotografía son sus conceptos (y la imaginación que resulta de esos conceptos); el programa de cámara está hecho para servir a este propósito" (43).

Las fotografías que aparecen en la antología de Diego no señalan quién fue el fotógrafo; sin embargo, la disposición corporal y el fondo donde se posicionan los retratados nos permiten observar cómo se autofiguran los poetas seleccionados. Como indica Jérôme Meizoz (2013: 253), durante el surgimiento de la era mediática, la figura del autor empezó a adquirir una nueva dimensión de espectacularidad que lo insertaba en la vida social. También refiere que esta figuración del autor en imágenes tendrá su gran desarrollo en los movimientos de vanguardia (Meizoz, 2013: 254), época en la cual se desenvuelven los poetas seleccionados por Diego, salvo el caso de Miguel de Unamuno, Manuel y Antonio Machado y Juan Ramón Jiménez, que ya poseían una obra consolidada y una trayectoria de vida distinta. Aun así, resulta importante tener en cuenta sus fotografías y cómo se relacionan sus posturas ante la cámara con la de los jóvenes poetas.

Estas fotografías de Poesía española abarcan distintas fechas: la más antigua data de 1923 y las más modernas de 1931. Las imágenes llevan abajo el nombre del retratado y el lugar donde fueron tomadas. A veces presentan a sólo un autor, como en los siguientes casos: Unamuno con un rostro serio, fotografiado de la cintura para arriba $y$, al fondo, con una escalera - al ser la foto tomada en Salamanca podemos suponer que se trata de la Universidad de dicha ciudad en donde era docente-. Las fotografías de los Machado nos los muestran de perfil, centrándose en el rostro - Manuel volteando a su izquierda y Antonio a su derecha-; de igual manera se observa a Larrea. Estas fotos de perfil hacen pensar que se buscaba dar cuenta de la mirada reflexiva de estos autores. En cambio, a Ramón Jiménez se le muestra sentado en una silla con las piernas cruzadas y la mirada dirigida posiblemente a una ventana. Semejante es la foto de Cernuda, sentado con las piernas cruzadas mirando al horizonte y no a la cámara. Ambas fotografías nos hacen partícipes de que estamos ante dos personas que se toman en serio su posición como poetas y videntes del fenómeno poético (Figura 3). Moreno Villa aparece de cuerpo completo y en la ciudad de Madrid, como igual lo hacen Salinas, Villalón y Altolaguirre, dando pie a la concepción del poeta moderno en la urbe. A Guillén se le aprecia casi todo el cuerpo, como a Diego; ambos permanecen ocultos de la rodilla para abajo - la foto de Guillén fue tomada en Murcia y se ve al fondo la ciudad, mientras que la de Diego fue tomada en Santander y se aprecia la calle-. Considero que ambas imágenes comparten características con las de Salinas, Villalón y Altolaguirre. Muchísimo menos rígidas son las fotografías de 


\section{Figura 3}

Retratos en comparación: Juan Ramón Jiménez y Luis Cernuda en la antología de Gerardo Diego
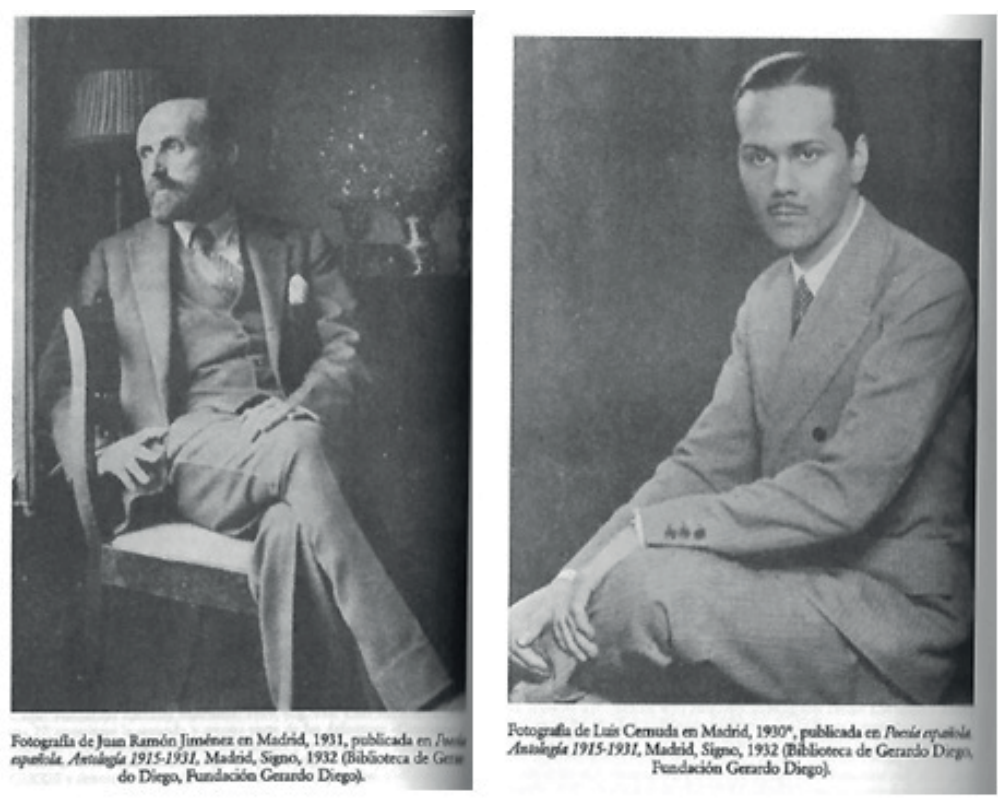

Fuente: Diego (2007).

Alonso, de cuerpo completo y sentado en un campo de Santander, y la de Aleixandre, acostado cerca del Guadarrama, como si se tratara de dos poetas más cercanos a la naturaleza que a la ciudad. Por otro lado, tenemos dos fotos en donde aparece el seleccionado junto con otros escritores. Es el caso de García Lorca, acompañado de Alberti detrás de un árbol bifurcado; y el de Alberti mismo, en donde se encuentra rodeado por Villalón y Altolaguirre en cuerpo completo y, al fondo, la ciudad de Madrid. El único que no presenta fotografía es Prados, ya que rehusó participar en la antología de Diego (Morelli: 1997, 193). Estas posturas que adoptan los poetas en sus fotografías marcan también el cómo se quieren concebir frente a un público y cómo quieren que su imagen sea distribuida en Poesía española. Antología 1915-1931.

Según Meizoz (2013),

En las prácticas literarias contemporáneas, el cuerpo del autor se hace igualmente presente. Aunque menos concertadas, las presentaciones públicas exigidas a los escritores (lecturas, firma de libros, entrevistas) o aseguradas por los colectivos (veladas con músicos, veladas declamatorias) son parte integral de las 
actividades, los autores encarnan sus escritos, ya se trate de promoverlos o de performarlos. (257)

Frente a este uso de las imágenes, la Antología del grupo poético de 1927 de Gaos (1965) sólo emplea la imagen del Centenario de Góngora para simbolizar al grupo de escritores. Sin embargo, en la reedición de Cátedra en 1975 se combina el uso de fotografías - los casos de Guillén y Aleixandre-, de pinturas - como en los casos de Alberti y Alonso- o dibujos — así figuran Salinas, Diego, Lorca y Cernuda-; pero no de todos tal como ocurre con Domenchina, Prados y Altolaguirre. En ninguna parte del libro se refiere de donde proceden estas imágenes. Lo importante a destacar es que frente a las fotos que sólo nos presentan a los autores de perfil, la pintura nos indica la postura de Alberti y Alonso como escritores o gente de letras (ambos sentados y con un libro o escribiendo) (Figura 4). En cambio, el dibujo adquiere mayor expresividad al darnos cuenta de elementos simbólicos que potencian al retratado como en el caso de García Lorca tocando el piano y con una guitarra al lado (Figura 5) o Cernuda, que también se presenta en la pose de gente de letras con un libro en la

\section{Figura 4}

Pintura de Dámaso Alonso en la antología de 1975 de Vicente Gaos

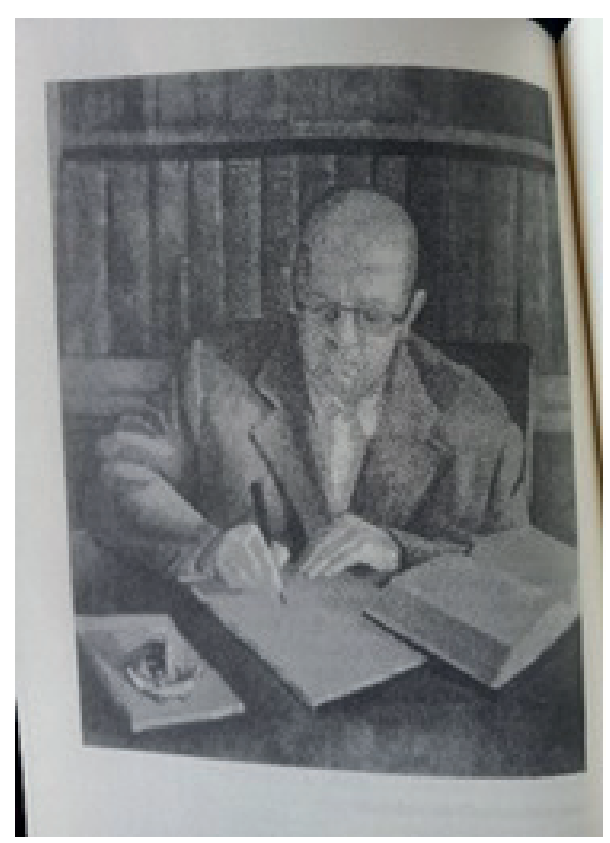

Fuente: Gaos (2019). 


\section{Figura 5}

Dibujo de Federico García Lorca en la antología de 1975 de Vicente Gaos

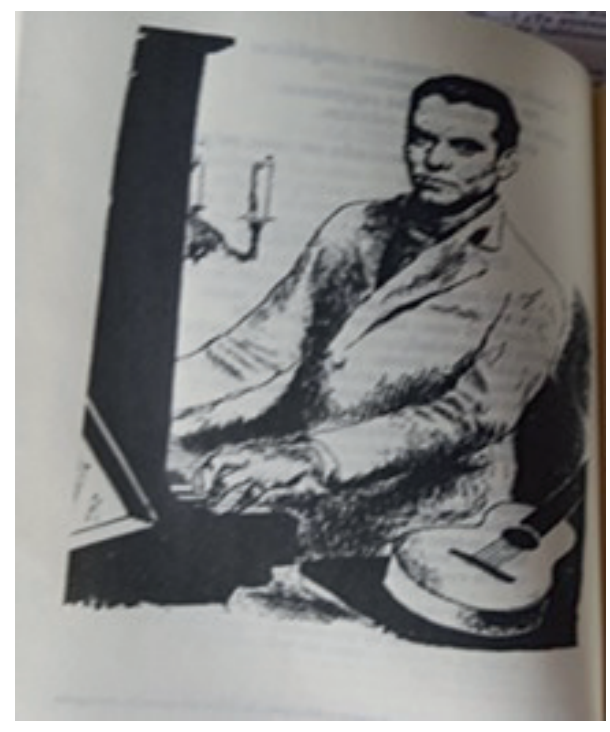

Fuente: Gaos (2019).

mano, el cuerpo apenas esbozado y con un rostro más definido. Teniendo en cuenta que Gaos no insertó imágenes en su antología publicada por Anaya, suponemos que éstas fueron puestas por Sahagún, quien amplió la antología, o por decisión de la misma editorial.

La Antología de los poetas del 27 de Cano (1982) vuelve a emplear fotografías, además de que indica en el pie de la imagen el fotógrafo o propietario de la foto o el archivo de origen; lo anterior resulta llamativo porque nos permite entender no sólo quién tiene acceso a esas imágenes sino por qué se escoge una determinada foto para establecer esas posturas autorales. En esta antología, aunque se presente al dueño de la imagen, debemos hacer notar que no se indica el año ni el lugar de la foto. Sin embargo, podemos realizar aproximaciones al origen de éstas por los elementos que nos dan: un ejemplo es la de Villalón, que se nos presenta en un campo de cultivo y detrás de él un caballo, por lo cual podemos deducir que la foto se tomó en su ganadería y un tiempo antes de que falleciera en 1930, claves que se confirman al leer la nota biobibliográfica (Cano, 1982: 39). En general se escogen fotografías que presentan una etapa de senectud de los poetas seleccionados, salvo en los casos de Villalón y García Lorca por su corta vida. La mayoría son imágenes tomadas que se centran en el rostro de los poetas, sea capturando el perfil o sea mirando al frente, como si allí residiera el 
genio de la creación poética. En este libro todos cuentan con su respectiva fotografía. No hay exclusiones.

Además, un aspecto interesante en la antología de Cano es su configuración en la contracubierta al ser mencionado según sus funciones en el campo literario: "José Luis Cano, crítico literario y poeta, gran conocedor de la generación del 27, ha realizado para selecciones austral la presente antología" (Cano, 1982: contracubierta). Junto a esto aparece una fotografía suya como parte del formato editorial de la colección. Además, en la página cuatro, se mostraba la foto del autor del libro (Figura 6) (Sánchez-Vigil y Olivera Zaldúa, 2012: 41), lo cual lo hace una figura autoral que nos da cuenta de su posición en el sistema literario al mostrarnos a un hombre sentado mirando casi directamente a la cámara y que tiene de fondo un librero, con una expresión afable que nos invita a leer su antología, como si de esa manera su presencia validara su labor de antólogo. Por otro lado, en la portada, el antólogo ocupa la posición y función de realizador de la "selección e introducción", con lo que se le reconoce su figura, mas no su rango de autor.

En el caso de Víctor de Lama, también se le enuncia en la contracubierta: "Víctor de Lama ha recogido en este volumen la selección que la transmisión histórica de la

Figura 6

Retrato fotográfico de José Luis Cano, Foto Woolf

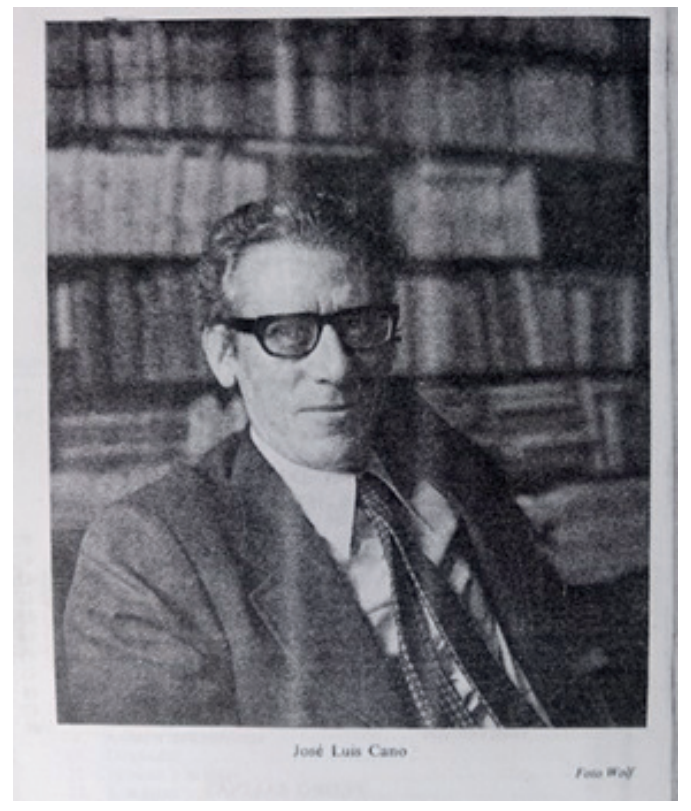

Fuente: Cano (1982). 
obra de este grupo ha depurado y consagrado como lo más representativo de todos sus integrantes, en conjunto y por separado" (Lama, 1997: contracubierta). Su antología, Poesía de la generación del 27. Antología crítica comentada (1997), muestra una breve semblanza del antólogo en la solapa del libro junto con una foto suya enfocada en su rostro que ve directamente la cámara (Figura 7). En esa parte del libro se indican sus grados académicos, su labor docente, su trabajo como investigador y labor como antólogo. Estas referencias curriculares buscan validar al autor de la antología dentro del campo de la investigación y docencia literaria, ya que no se trata de un antólogo-poeta como en el caso de Diego, Gaos y Cano. Lo establecido en la contracubierta y el currículo señalado en la solapa dota de autoridad a Lama como recopilador de la poesía de estos escritores ya que, aparentemente, aplica un criterio objetivo y académico como se desprende del mismo título del libro.

Poesía de la generación del 27. Antología crítica comentada presenta fotografías de todos los que aparecen en la sección "Poetas principales", además de que configura a los escritores no sólo con un apartado biobibliográfico, sino añadiendo las poéticas que aparecían en la antología de Diego de 1932. Las fotos sólo indican quién

Figura 7

Fotografía de Víctor de Lama en la solapa de su antología

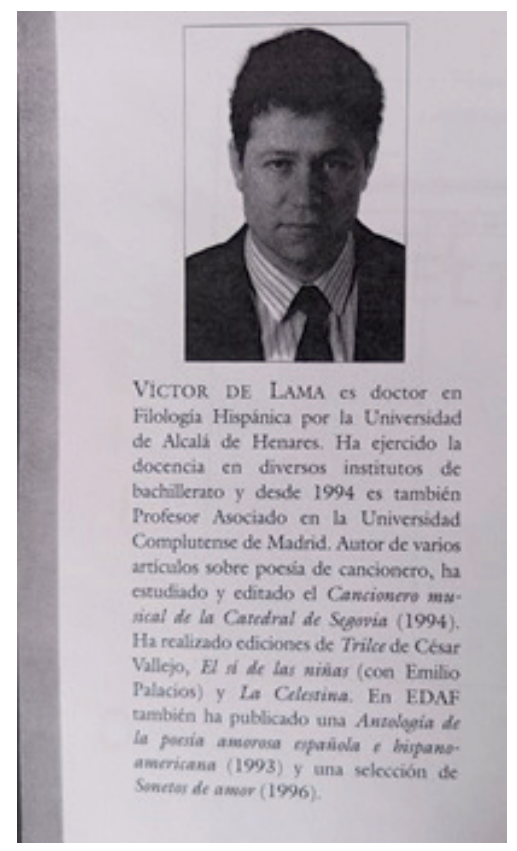

Fuente: Lama (1997). 
es el retratado, pero no dan cuenta ni del año, ni del lugar, ni del propietario de la imagen; todas éstas se centran en el rostro, el cual puede estar mirando al frente o de perfil. La mayoría de los poetas aparecen con una edad bastante mayor, como en el caso de Alberti o de Alonso; algunas veces en una etapa intermedia, como Guillén; y sólo bastante jóvenes García Lorca y Altolaguirre. El libro se divide en dos secciones: la primera sección titulada "Poetas principales" presenta las fotografías de los diez poetas seleccionados; mientras que, en la segunda sección, "Otros poetas del 27" -en donde se selecciona poesía de Villalón, Larrea, Domenchina e Hinojosa- no se utiliza ninguna fotografía para figurarlos. Inclusive el ocultamiento de la imagen parece ser intencional porque se presenta una página en blanco antes del apartado biobibliográfico. En la antología de Cano sí se presentaba la imagen de Hinojosa y Villalón, y en la de Diego sí se había incluido la fotografía de Larrea. Entre las antologías que hemos visto en este trabajo, el único que no ha presentado fotografías en ningún caso es Domenchina. Los poetas de esta última sección también representan a los autores con menos poesías seleccionadas en este libro, como si su inclusión sólo fuera un pequeño apéndice para referir a una ampliación del canon de los diez poetas siempre seleccionados.

Estos usos de las fotografías individuales por parte de los antólogos o de la editorial evidencia que el uso de ellas en las antologías permite figurar y valorar a los poetas desde su presencia escénica como autores. En el caso de la antología de Diego, este uso reforzaba una idea de la modernidad y del escritor moderno que no sólo escribe, sino que se posiciona civilmente (reflejado en las biografías), intelectualmente (poéticas) y visualmente (fotografías). La segunda edición de la antología de Gaos hace un uso caprichoso de estos elementos visuales y, aun así, permite figurar y asumir posturas de los escritores seleccionados. La antología de Cano emplea estos recursos de manera congruente para que cada uno de los seleccionados figure en imagen en el libro, dando rostro a los que luego han sido invisibilizados, como Prados e Hinojosa. En cambio, la antología de Lama, al diferenciar a los "principales" de los "otros", legitima con la imagen a los que conforman el "canon" de dicha Generación de 1927 e invisibiliza a los que considera sólo un apéndice. Además, en la antología de Diego de 1932, de Gaos y de Lama, los que no cuentan con imagen tienen una selección menor de poemas. El antólogo y la editorial emplean, en ese sentido, a la antología como dispositivo que permite al sujeto adquirir una proyección visual de los poetas seleccionados, y que oculta a unos y legitima a otros mediante el retrato. Observamos un mayor uso del retrato fotográfico que se centra en el rostro, como en 
Cano y Lama, mientras que se ha dejado de lado el uso de fotografías distintas, como el caso de las que aparecen en la antología de Diego.

Existe un último elemento visual que se presenta en el corpus de antologías que se ha revisado. Se trata de la imagen del Centenario de Góngora en Sevilla en 1927, la cual es empleada en las portadas de los libros para dotar de una imagen simbólica a los poetas seleccionados. Esta fotografía empezó a circular en los periódicos de Sevilla el 18 de diciembre de 1927, y en realidad se trata de tres versiones distintas: en el periódico La Unión, el fotógrafo fue Dubois (Eduardo Rodríguez Cabezas); en El Noticiero Sevillano, Juan José Serrano; y en El Liberal, no se indica quién. Esta última se ha adjudicado a Pepín Bello (José Bello Lassierra) y se ha revestido la historia de manera fabulosa, seguramente por tratarse de uno de los amigos más íntimos de la Generación de 1927 (Rondón, 2016). Las tres fotografías sólo presentan pequeños cambios y en general todos muestran la misma posición. En ella aparecen, de izquierda a derecha: Rafael Alberti, Federico García Lorca, Juan Chabás, Mauricio Bacarisse, Miguel Romero Martínez y Blanco Garzón, Jorge Guillén, José Bergamín, Dámaso Alonso y Gerardo Diego. Si contrastamos los nombres de los escritores retratados en esta foto con los poetas seleccionados en las antologías, observamos que no están presentes Pedro Salinas, Vicente Aleixandre, Emilio Prados, Luis Cernuda ni Manuel Altolaguirre. Mucho menos están retratados ahí Hinojosa, Larrea, Domenchina y Villalón. Pese a las ausencias, la fotografía se ha vuelto emblemática y simbólica de dicha agrupación poética por representar el final de una serie de actos en conmemoración del Centenario de Luis de Góngora en el año de 1927, fecha importante porque en ese momento permitió a jóvenes autores unirse y perfilar un programa de renovación poética. No ha de sorprendernos entonces que lo simbólico no radique en los que están presentes en la foto, sino en el acontecimiento mismo y, por ende, su distribución a lo largo de historias literarias, antologías y conmemoraciones ha terminado inmortalizando ese momento en el imaginario del campo literario. En ese sentido, esta foto ha cumplido con una distribución masiva al reproducirse en distintos medios que dan a conocer a esta agrupación poética: "Las fotografías son heraldos de la sociedad posindustrial general; el interés se desplaza en ellas del objeto a la información, y la propiedad se convierte, a través de ellas, en una simple categoría útil. Los canales de distribución, los media, codifican el significado final de las fotografías" (Flusser, 1990: 50).

La distribución de la fotografía del Centenario de Góngora se ve reflejada al emplearse en las cubiertas de la antología de Gaos publicada en Cátedra en 1974 
- el responsable de ella es Mauro Cáceres - y en la de Lama, producida en EDAF en 1997, junto con su empleo en la contraportada de la de Gaos en su edición en Anaya en 1965. Aunque estas tres antologías utilizan esta imagen, se diferencian porque hacen modificaciones de la foto emblemática. Estas alteraciones de la imagen obedecen al estilo que toma cada editorial para sus cubiertas: en el caso de Cátedra, que emplea un fondo negro, la imagen aparece en el centro superior de la cubierta y se recurre al collage para editarla - aparecen las imágenes de los fotografiados en blanco y negro, pero el fondo del Salón de Actos de la Real Sociedad Económica del País de Sevilla se caricaturiza, seguramente para dar cuenta de la afiliación de estos poetas a la vanguardia-. En el caso de EDAF sólo se recurre a desdibujar el fondo, difuminar a los fotografiados y mezclar el color de la fotografía con el fondo amarillento. El empleo de esta foto para simbolizar a toda una generación de poetas resulta interesante porque dota a una imagen de capacidad emblemática para ser característica de la Generación de 1927, ya que se capta en ella todo lo simbólico e importante que fue el Centenario de Góngora, a pesar de que los retratados no sean los que siempre se seleccionan en las antologías. Debido a esto, el uso de esta fotografía marca un imaginario de lo que se concibe de esta generación. Por ello esta ilustración valida y legitima a los poetas y a la antología confeccionada (Figura 8).

Estas imágenes, principalmente, se han centrado en el rostro de los escritores, como observamos en las antologías de Cano y Lama (Figura 9). Por otra parte, en las antologías de Diego y de Gaos se recurre a retratos con mayor diversidad de elementos. También revisamos cómo algunas de estas antologías seleccionan la fotografía del antólogo para darle validez como autor del compendio, tal como se puede desprender de las de Cano y Lama. Finalmente, estos libros han recurrido de manera asidua a la fotografía grupal del Centenario de Góngora en Sevilla para simbolizar a estos poetas como parte de un grupo. Ante estas observaciones, deberemos considerar que existen otras antologías sobre la Generación del 27 que no se tuvieron en cuenta en este estudio, por lo que convendría que en futuros acercamientos se realizara un trabajo más exhaustivo al respecto.Las imágenes que se emplean en estas antologías figuran a los poetas seleccionados, pero también simbolizan la unidad de la Generación de 1927, además de que dotan al antólogo de autoridad. La conjunción de estas fotografías con los paratextos, los textos del antólogo y los poemas de los seleccionados otorgan unidad y coherencia al material del libro para legitimar su contenido y su función en el sistema literario. De esta manera observamos que el dispositivo de la antología se transforma en la galería que da cuenta de una serie de imágenes de grupo, de los 


\section{Figura 8}

\section{Comparativa del uso de la fotografía del Centenario de}

\section{Góngora en Sevilla}
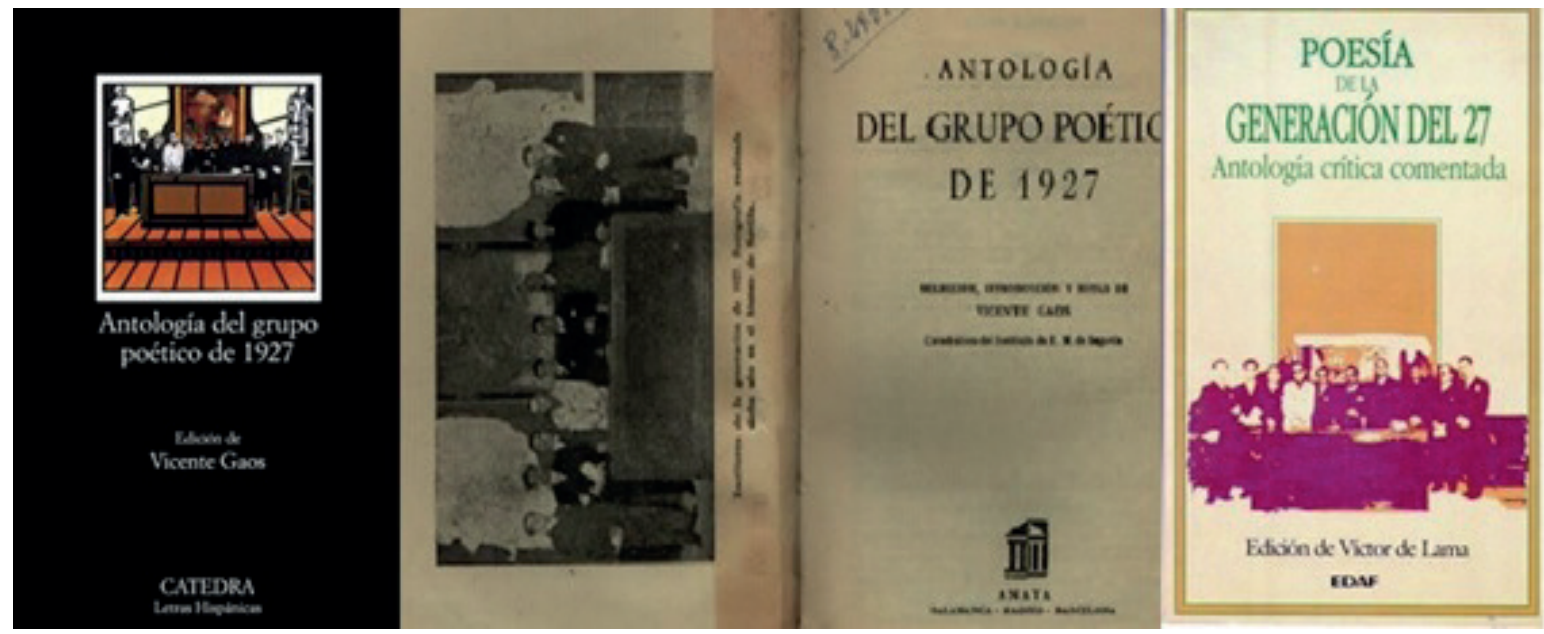

Fuente: Cubierta de Antología del grupo poético de 1927 de Vicente Gaos (Cátedra) recuperada de https://www.catedra.com/imagenes/libros/grande/9788437600536-antologia-del-grupo-poetico-de-1927.jpg. Cubierta de Poesía de la generación del 27. Antología crítica comentada de Víctor de Lama recuperada de https://pictures.abebooks.com/inventory/md/md9151426911.jpg.

\section{Figura 9}

Fotografías de Vicente Aleixandre en las antologías de José Luis Cano y Víctor de Lama

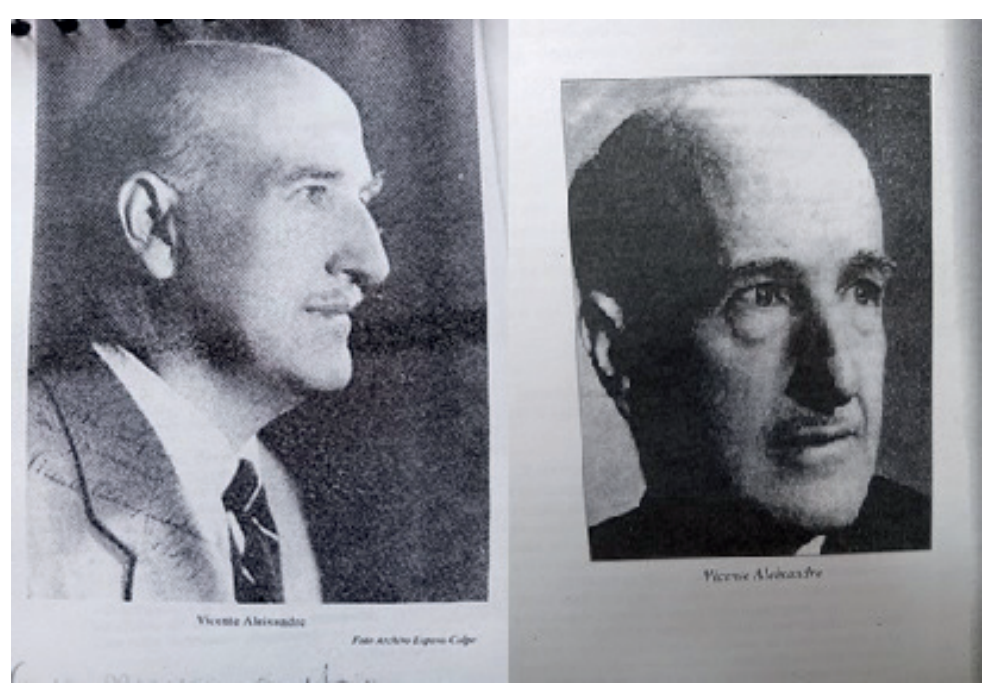

Fuente: Cano (1982) y Lama (1997) 
poetas seleccionados y del antólogo; además de la correspondiente selección poética. Tan sólo pensemos en cómo Cano le da cabida a la imagen de cada uno de los seleccionados, mientras que Lama sólo se la otorga al grupo principal. Sin embargo, cabe aclarar que el uso de imágenes y figuras de autor presentado en estas cinco antologías puede ser ampliado si se considera el uso de otros elementos visuales, como la ilustración de poemas en las antologías de Ortega y Roldán, o el uso de imágenes de revistas y portadas de libros, como se observa en los casos de Ramoneda, Cerrillo o Cifo González La observación de las múltiples posibilidades de este tipo de recursos requiere de un estudio aún más exhaustivo de su materialidad para poder entender los distintos elementos y reglas de combinación del repertorio antológico.

\section{Referencias bibliográficas}

Anderson, Andrew A. (2005). El veintisiete en tela de juicio. Examen de la historiografía generacional y replanteamiento de la vanguardia histórica española. Gredos.

Cano, José Luis. (1982). Antología de los poetas del 27. Espasa; Calpe.

Cerrillo, Pedro C. (2002). Antología poética: grupo del 27. Akal.

Cifo gonzález, Manuel. (1996). Antología poética de la generación del 27. Santillana.

ChARTIER, Roger. (2009). "Del códice a la pantalla: trayectorias de lo escrito". En Adriana de Teresa Ochoa (Coord.), Circulaciones: trayectorias del texto literario (pp.17-30). Bonilla Artigas Editores; UNAM.

Diego, Gerardo. (2007). Poesía española [Antologías] (José Teruel, Ed.). Cátedra.

Díez De Revenga, Francisco Javier. (1987). Panorama crítico de la generación del 27. Castalia.

Díez De ReVenGA, Francisco Javier. (2004). Las vanguardias y la Generación del 27. Síntesis.

Díez de ReVenga, Francisco Javier. (2007). Antología poética de la Generación del 27. Centro Cultural de la Generación del 27; Área de la Cultura y Diputación de Málaga; Consejería de Educación de la Junta de Andalucía.

Even-Zohar, Itamar. (1999). "Factores y dependencias en la cultura. Una revisión de la teoría de los Polisistemas”. En Montserrat Iglesias Santos (Ed.), Teoría de los Polisistemas (pp. 23-52). Arco/Libros. 
Flusser, Vilém. (1990). Hacia una filosofía de la fotografía. Trillas.

GaOs, Vicente. (1965). Antología del grupo poético de 1927. Anaya.

GaOs, Vicente. (2019). Antología del grupo poético de 1927. Cátedra.

García, Miguel Ángel. (2017). “Historiografía, canon, compromiso: los poetas del 27 en las antologías (1932-1965)”. En Miguel Ángel García (Coord.), El compromiso en el canon. Antologías poéticas españolas del último siglo (pp. 16-77). Tirant.

GarCía, Miguel Ángel. (2016). "Los poetas del 27 en el canon del compromiso y el canon de las antologías (1932-1934)”. Anthropos: cuadernos de cultura crítica y conocimiento, (245), 25-44.

Garrote Bernal, Gaspar. (1994). Trayectorias poéticas del veintisiete. Magisterio Español y Casals.

GonZÁlez, Ángel. (2004). El grupo poético de 1927. Antología. Visor.

González Aktories, Susana. (1996). Antologías poéticas en México. Praxis.

González Muela, Joaquín; Rozas, Juan Manuel. (1966). La generación poética de 1927. Estudio, bibliografía y documentación. Alcalá.

Guillén, Claudio. (1987). Entre lo uno y lo diverso. Introducción a la literatura comparada. Crítica.

Guzmán Moncada, Carlos. (2000). De la selva al jardín. Antologías poéticas hispanoamericanas del siglo XIX. UNAM.

Issorel, Jacques. (1984). “Note sur les anthologies de la génération de 1927”. Bulletin hispanique, 86(1-2), 201-204. https://doi.org/10.3406/hispa.1984.4527

Issorel, Jacques. (1993). “Note (n²) sur les anthologies de la génération de 1927”. Bulletin hispanique, 95(2), 713-717. https://doi.org/10.3406/hispa.1993.4812

Issorel, Jacques. (2000). "Note ( $\left.\mathrm{n}^{\circ} 3\right)$ sur les anthologies de la génération de 1927". Bulletin hispanique, 102(1), 249-259. https://doi.org/10.3406/hispa.2000.5040

Lama, Víctor de. (1997). Poesía de la generación del 27. Antología crítica comentada. Edaf.

Maingueneau, Dominique. (2015). “Escritor e imagen de autor”. Tropelías. Revista de Teoría de la Literatura y Literatura Comparada, (24), 17-30. https://doi.org/10.26754/ojs_ tropelias/tropelias.2015241139 
Meizoz, Jérôme. (2013). “Escribir es entrar en escena’: La literatura en persona” (Juan Manuel Mogollón Zapata, Trad.). Estudios: Revista de Investigaciones Literarias y Culturales, 21(42), 253-269.

Morelli, Gabriele. (1997). Historia y recepción de la "Antología" poética de Gerardo Diego. Pretextos.

NúÑEZ, Estuardo. (1959). “Teorías y procesos de la antología”. Cuadernos Americanos, 106(5), 257-267.

Ortega, Esperanza. (1987). Antología de la generación del 27. Anaya.

Palenque, Marta. (2007). "La poesía española del siglo xx en las antologías de época y de grupo (1902-1941)”. En Alfonso García Morales (Ed.), Los museos de la poesía. Antologías modernas en español. 1982-1941 (pp. 405- 458). Ediciones Alfar.

Pozuelo Yvancos, José María. (2009). "Las poéticas de la Antología de Gerardo Diego" En Poética de poetas: teoría crítica y poesía (pp. 123-139). Biblioteca Nueva.

Ramoneda, Arturo. (1990). Antología de la generación del 27. Castalia.

Reyes, Alfonso. (1997). “Teoría de la antología”. Obras completas XIV (pp. 132-138). Fondo de Cultura Económica.

Reyes Cano, Rogelio. (1987). "El grupo poético del 27 y Sevilla: Crónica de un acto fundacional”. Anales de filología hispánica, (3), 5-24.

RICART, José. (2014). La generación del 27. Cátedra.

Rodiek, Christoph. (1998). “Las antologías del 27 -Enfoques y (des)ajustes”. En Harald Wentzlaff-Eggebert (Ed.), Nuevos caminos de la investigación de los años 20 en España (pp. 151-161). Max Neimeyer.

Roldán, Amalia; VAlle, Lola. (2007). Ochenta poemas de la Generación del 27. Centro Cultural de la Generación del 27; Área de la Cultura y Diputación de Málaga; Consejería de Educación de la Junta de Andalucía.

Rondón, José María. (2016, 18 de diciembre). "Las tres fotografías de la Generación del 27” (en línea). Diario de Sevilla, Cultura. Recuperado el 11 de febrero del 2021 de https://www.diariodesevilla.es/ocio/fotografias-Generacion_0_1091591245.html

Ruiz Casanova, José Francisco. (2007). Anthologos: poética de la antología poética. Cátedra. 
SÁnchez-Vigil, Juan Miguel; Olivera Zaldúa, María. (2012). "La Colección Austral: 75 años de cultura en el bolsillo (1937-2012)”. Palabra Clave (La Plata), 1(2), 29-47.

Soria Olmedo, Andrés. (2007). Las vanguardias y la generación del 27. Visor.

Woodall, Joanna. (1997). "Introduction: Facing the Subject". En J. Woodall (Ed.), Portraiture: Facing the Subject (pp. 1-25). Manchester University Press.

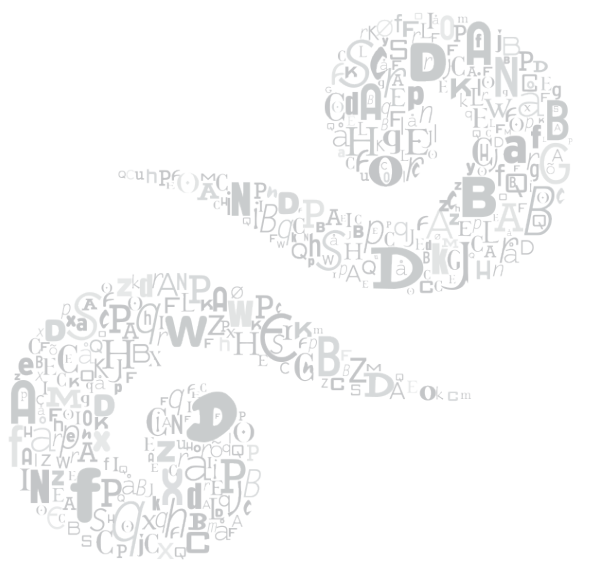

